\title{
Effects of Hatch Window and Nutrient Access in the Hatcher on Performance and Processing Yields of Broilers Reared with Equal Hatch Window Representation
}

\author{
Joshua R. Deines ${ }^{1} \mathbb{1}$, F. Dustan Clark ${ }^{1}$, Doug E. Yoho ${ }^{1}$, R. Keith Bramwell ${ }^{2}$ and Samuel J. Rochell ${ }^{1, *}$ \\ 1 Department of Poultry Science, University of Arkansas, Fayetteville, AR 72701, USA; \\ joshuadeines@gmail.com (J.R.D.); fdclark@uark.edu (F.D.C.) \\ 2 Jamesway Incubator Company Inc., Cambridge, ON N1R 7L3, Canada; keith.bramwell@jamesway.com \\ * Correspondence: rochell@uark.edu
}

check for updates

Citation: Deines, J.R.; Clark, F.D.; Yoho, D.E.; Bramwell, R.K.; Rochell, S.J. Effects of Hatch Window and Nutrient Access in the Hatcher on Performance and Processing Yields of Broilers Reared with Equal Hatch Window Representation. Animals 2021, 11, 1228

https://doi.org/10.3390/ani11051228

Academic Editors: Laura Star, Jasper Heerkens and Sander Lourens

Received: 18 March 2021

Accepted: 15 April 2021

Published: 23 April 2021

Publisher's Note: MDPI stays neutral with regard to jurisdictional claims in published maps and institutional affiliations.

Copyright: (c) 2021 by the authors. Licensee MDPI, Basel, Switzerland. This article is an open access article distributed under the terms and conditions of the Creative Commons Attribution (CC BY) license (https:// creativecommons.org/licenses/by/ $4.0 /)$
Simple Summary: In commercial hatcheries, hatched broiler chicks remain in the hatcher without feed or water until all chicks are pulled from the hatching cabinet. Subsequent hatchery holding and transport periods can further delay nutrient access, potentially causing dehydration and limiting the bird's growth potential. This can possibly be mitigated by providing feed and water in the hatching cabinet to promote immediate nutrient access to chicks after hatching. In the current experiment, chicks hatched in baskets modified to supply feed and water were compared with those hatched in standard baskets in regards to their organ weights, growth performance to $42 \mathrm{~d}$, and processing yields. Additionally, chicks were identified according to moment of hatch within the hatch window to evaluate this factor and its potential interaction with nutrient access. Chicks from hatching baskets with nutrient and water access had heavier body weights during the first $4 \mathrm{wk}$ of growth, but were otherwise similar to chicks from standard baskets in growth performance and meat yield, regardless of the timing of their hatch. This indicates that broilers may be able to compensate for some degree of delayed feed and water access associated with their timing of hatch and subsequent holding and transport.

Abstract: The objective of this experiment was to investigate the effects of feed and water availability in hatching baskets on broiler performance, processing yield, and organ weights while considering the influence of hatch window. Cobb 500 eggs were transferred into illuminated hatchers with two hatching basket types [control (CTL) hatching baskets with no nutrients provided or baskets containing feed and water (FAW)]. Chicks were pulled sequentially to establish four hatch window periods (HWP): early, pre-peak, post-peak, or late. Chicks were then held for $4 \mathrm{~h}$ at the hatchery without nutrient access and subsequently reared in 26 floor pens designated as CTL $(n=13)$ or FAW $(n=13)$, with 13 chicks from each of the 4 HWP per pen (52 chicks per pen). At $43 d, 16$ males from each pen were processed. Chicks from FAW baskets were $1 \mathrm{~g}$ heavier $(p<0.001)$ than those from CTL baskets at placement and were heavier through $28 \mathrm{~d}(p=0.003)$ but similar $(p>0.05)$ in body weight (BW) for the remainder of the $42 \mathrm{~d}$. No differences $(p>0.05)$ in feed conversion ratio, mortality, or processing data were observed between CTL and FAW groups. Early-hatching chicks were lighter $(p<0.001)$ than those from all other HWP at placement, but were only lighter $(p<0.001)$ than the post-peak group by $42 \mathrm{~d}$. In summary, it was found that hatching basket nutrient access increased the BW of broilers during the first $4 \mathrm{wk}$ of growth, with no other effects on performance or yield. Also, earlier-hatching chicks were generally able to compensate for a lighter placement BW.

Keywords: hatch window; hatcher; feed access; broiler

\section{Introduction}

The modern broiler has been selected for rapid growth, allowing a desired market weight to be reached in a shorter amount of time compared with broilers from the past [1] 
This growth is initiated once the chick begins consuming exogenous feed, which it efficiently converts to body tissue. Feed intake of newly hatched chicks has been shown to increase yolk secretions to the small intestine and increase glucose and methionine uptake [2]. Further, Noy and Sklan [3] reported that sawdust fed to chicks after hatch resulted in a higher BW at $4 \mathrm{~d}$ post-hatch compared to a control, indicating that non-nutritive material present in the gastrointestinal tract may also initiate a similar physiological response. As the chick transitions from endogenous to exogenous nutrient sources, the digestive system undergoes significant alterations as it matures with age, and providing feed to chicks soon after hatch increases the rate of this development. Conversely, chick fasting and delayed placement studies have reported depressions in BW that persist to market age, decreased uniformity, and higher mortality [4-6]. Prior to water and feed access, chicks are relying on their remaining yolk sac to provide energy [7] and nutrients for growth, and yolk sac degradation accounts for the majority of BW loss during the first $24 \mathrm{~h}$ after hatch [4].

In addition to processing at the hatchery and transportation to the farm, the time at which a chick hatches determines how long it has until its first access to water and feed. The hatch window is generally 24 to $48 \mathrm{~h}$ for commercially produced broilers and therefore earlier hatching chicks have considerably more time out of the egg until placement. While chicks are held in the hatcher without water and feed, they rapidly begin to decrease in BW as a result of dehydration and yolk utilization $[8,9]$.

Early feeding methods such as in ovo and hatcher feeding have been investigated as strategies to provide immediate access to nutrients and avoid the negative effects of delayed placement [3,10-12]. Feeding in hatching baskets is a method that allows chicks access to nutrients immediately after hatching and becoming ambulatory, and Sklan et al. [8] showed that this is an effective approach for decreasing the amount of BW chicks and poults lose while in the hatcher, particularly for earlier hatchers. Similarly, Hollemans et al. [12] demonstrated that chicks provided nutrients in their hatching baskets have higher BW, up to $28 \mathrm{~d}$, than chicks without. However, compensatory growth of fasted and early hatching chicks may diminish these early benefits depending on the final slaughtering age of the birds $[13,14]$.

Clearly, the differing degrees of success reported for various early feeding strategies warrant additional investigation. Further, existing literature on early post-hatch feeding has focused on comparing fed birds to those exposed to fasting periods of $24 \mathrm{~h}$ or more after pull of hatch, but such extended fasting periods are not typically observed in practical broiler production. With the increasing availability of commercial systems that facilitate nutrient access in the hatcher, the potential benefits of this specific early feeding strategy need to be evaluated. Under these systems, the time at which a chick emerges from the shell within the hatch window will dictate their opportunity for nutrient consumption before pull and influence the potential for water access to offset dehydration. This may affect both weight and physiological status at placement as well as subsequent feeding behavior. As such, the current experiment was conducted to examine the effects of providing nutrient access in the hatching baskets on the subsequent live performance and processing yields of chicks subjected to industry-relevant holding times and reared with equal hatch window representation.

\section{Materials and Methods}

\subsection{Egg Source and Incubation}

Fertile eggs from a single, 36-wk-old Cobb MV $\times 500$ breeder flock were sourced from a commercial broiler integrator. Eggs were transported to the University of Arkansas Poultry Research Farm hatchery and held overnight in an egg storage room at $18.3^{\circ} \mathrm{C}$. A total of 2520 eggs were then set in a single machine (Ps500 Jamesway Incubator Company, Inc., Cambridge, ON, Canada) and incubated using a common broiler profile of $37.6{ }^{\circ} \mathrm{C}$ at $55 \%$ relative humidity $\left(29.4^{\circ} \mathrm{C}\right.$ wet bulb) from 0 to $18 \mathrm{~d}$. Eggs were turned every hour. 


\subsection{Nutrient Access and Hatch Window}

At $18 \mathrm{~d}$ of incubation, eggs were transferred to the hatcher (Ps500 Jamesway Incubator Company, Inc. Cambridge, ON, Canada) set at $36.7^{\circ} \mathrm{C}$ and $54 \%$ relative humidity $\left(27.8^{\circ} \mathrm{C}\right.$ wet bulb) until time of pull at $504 \mathrm{~h}$. The hatcher was equipped with LED lighting to provide approximately 21.5 lux to the interior in the hatch baskets. Incubated eggs were randomly assigned to 15 control (CTL) hatching baskets with no nutrients provided and 15 baskets containing feed and water (FAW). Standard hatch baskets were modified by creating a center divider. In each basket, 84 eggs were placed on one side, and the other side was devoid of eggs and configured to provide the CTL or FAW (Figure 1) experimental treatment. After hatching, chicks were then moved to the experimental side of the basket as described in Figure 1. Feed and water were provided ad libitum in $50 \mathrm{~mL}$ reagent reservoirs (89094-680 VWR International, West Chester, PA, USA) with each FAW basket containing 3 reservoirs of water and 3 reservoirs of feed. The feed provided in FAW baskets was the same crumbled starter subsequently fed to all chicks at placement (Table 1).

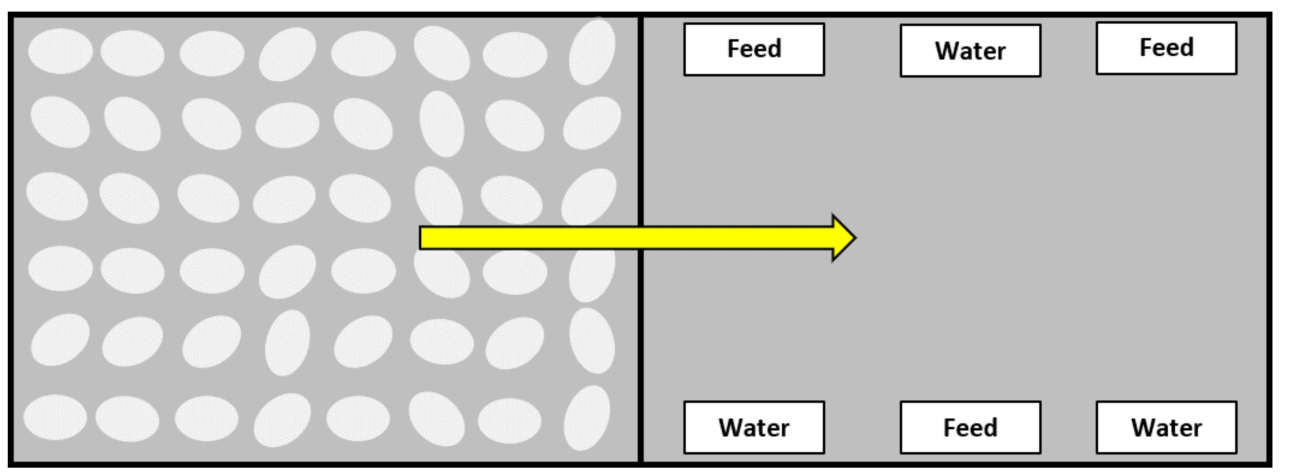

Figure 1. Layout of experimental hatching baskets. A standard hatching basket was divided down the center using mesh wire. At transfer, 84 eggs were placed in one side. At the conclusion of each hatch window period (HWP), hatched chicks were physically moved from the egg side of the basket to the treatment side that was without (control, CTL) or with feed and water (FAW).

In addition to nutrient access in the hatching basket, a sub-plot treatment factor included hatch window period (HWP). A pilot trial was conducted a week in advance by hatching eggs from the same breeder flock to determine the spread of hatch and define a hatch window. Based on these data, it was determined that the hatch window be divided into four HWP based upon number of h before pull at $504 \mathrm{~h}$ : early (30 to $24 \mathrm{~h}$ ), pre-peak ( 24 to $18 \mathrm{~h}$ ), post-peak (18 to $12 \mathrm{~h}$ ), and late (12 to $6 \mathrm{~h}$ ). Each HWP represented approximately $25 \%$ of the total hatch time. At the end of each HWP, all hatched chicks were removed from the egg side of the basket, tagged for identification, and placed into the experimental side of the basket. A chick was defined as hatched once fully and independently cleared from the shell. The HWP in which a chick hatched established the amount of time chicks had access to the experimental hatching baskets (CTL or FAW). Chicks in early, pre-peak, post-peak, and late HWP had $24 \mathrm{~h}, 18 \mathrm{~h}, 12 \mathrm{~h}$, of $6 \mathrm{~h}$ access to experimental hatching baskets, respectively. No chicks hatched more than $30 \mathrm{~h}$ before pull, and the relatively few chicks that hatched within $6 \mathrm{~h}$ of pull were not used in this experiment. Hatchability was not measured as a function of basket treatment, but overall hatchability was $87 \%$. 
Table 1. Ingredient and calculated nutrient composition of common diets.

\begin{tabular}{cccc}
\hline Item & Starter (0 to 14 d) & Grower (14 to 28 d) & Finisher (28 to 42 d) \\
\hline Corn & Ingredient composition, \% & \\
Soybean meal (46.3\%) & 60.98 & 64.72 & 69.55 \\
Poultry fat & 34.30 & 30.14 & 25.15 \\
Limestone & 1.16 & 1.87 & 2.33 \\
Dicalcium phosphate & 1.11 & 1.07 & 1.02 \\
Sodium chloride & 1.05 & 0.92 & 0.74 \\
DL-methionine & 0.44 & 0.44 & 0.40 \\
L-lysine & 0.32 & 0.26 & 0.25 \\
L-threonine & 0.21 & 0.17 & 0.20 \\
Mineral premix ${ }^{1}$ & 0.09 & 0.07 & 0.09 \\
Vitamin premix ${ }^{2}$ & 0.10 & 0.10 & 0.10 \\
Choline chloride $(60 \%)$ & 0.10 & 0.10 & 0.10 \\
Selenium premix (0.06\%) & 0.05 & 0.04 & 0.04 \\
Coccidiostat ${ }^{3}$ & 0.02 & 0.02 & 0.02 \\
Phytase ${ }^{4}$ & 0.05 & 0.05 & - \\
Calculated nutrient composition, \% unless otherwise noted & 0.03 \\
AME , kcal $/$ kg $_{\text {CP }}$ & 3008 & 3086 & 3167 \\
Digestible Lysine $_{\text {Digestible TSAA }}$ & 21.45 & 19.65 & 18.00 \\
Digestible Threonine & 1.18 & 1.05 & 0.95 \\
Calcium & 0.89 & 0.80 & 0.74 \\
Available phosphorus & 0.77 & 0.69 & 0.65 \\
\hline
\end{tabular}

${ }^{1}$ Supplied the following per kg of diet: vitamin A, 6350.29 IU; vitamin $\mathrm{D}_{3}, 4535.92 \mathrm{ICU}$; vitamin $\mathrm{E}, 45.36 \mathrm{IU}$ vitamin $\mathrm{B}_{12}, 0.01 \mathrm{IU}$; menadione, $1.24 \mathrm{mg}$; riboflavin, $5.44 \mathrm{mg}$; d-pantothenic acid, $8.16 \mathrm{mg}$; niacin, $31.75 \mathrm{mg}$; folic acid, $0.73 \mathrm{mg}$; pyridoxine, $2.27 \mathrm{mg}$; thiamine, $1.27 \mathrm{mg}$; biotin, $0.07 \mathrm{mg} .{ }^{2}$ Supplied the following per $\mathrm{kg}$ of diet: calcium, $55.5 \mathrm{mg}$; manganese, $100 \mathrm{mg}$; magnesium, $27 \mathrm{mg}$; zinc, $100 \mathrm{mg}$; iron, $50 \mathrm{mg}$; copper, $10 \mathrm{mg}$; iodine, $1 \mathrm{mg}$ ${ }^{3}$ Bio-Cox ${ }^{\circledR}$ 60, Huvepharma, Peachtree City, GA, USA (salinomycin sodium). ${ }^{4}$ OptiPhos ${ }^{\circledR} 2000$ PF, Huvepharma, Peachtree City, GA, USA.

\subsection{Growout, Sampling, and Processing}

At $504 \mathrm{~h}$, experimental baskets were removed from the hatcher. Chicks were segregated by treatment combination. Subsequently, chicks of the same basket treatment (CTL or FAW) were randomly selected by HWP and placed into a chick box designated as CTL or FAW (13 boxes per basket type) to achieve an equal distribution of 14 chicks from each of the 4 HWP (56 chicks total per box). Chicks were held at the hatchery in these boxes for $4 \mathrm{~h}$ to simulate commercially relevant processing and holding times, and no nutrients were provided for any chicks during this time. At the conclusion of the holding time, 4 chicks from each box (1 per HWP) were randomly selected and euthanized for yolk and liver sampling. The other chicks were transported to an experimental rearing facility for placement.

All 52 remaining chicks from each box were placed in a single floor pen to assess live performance during a $42 \mathrm{~d}$ experiment. The pens measured $1.52 \times 3.05 \mathrm{~m}$ and contained fresh pine shavings. Each pen had 2 hanging feeders with commercial feed pans and a single water line with 10 nipples. There were 13 replicate pens of FAW and CTL nutrient access treatments, with each pen containing 13 chicks from each of the 4 HWP. At $3 \mathrm{~d}$ post-hatch, 4 chicks from each pen (1 per HWP) in each of the 26 pens (13 CTL and 13 FAW) were again randomly selected and euthanized for yolk sacs and liver sampling. Bird weights and feed consumption were recorded weekly by pen. Individual bird weights were taken at $21 \mathrm{~d}$ and $42 \mathrm{~d}$ to assess uniformity. Mortality and associated weights were recorded daily. Common starter ( 0 to $14 \mathrm{~d}$ ), grower (14 to $28 \mathrm{~d}$ ), and finisher ( 28 to $42 \mathrm{~d}$ ) feeds (Table 1) and water were provided ad libitum. Feed was removed from the pens $10 \mathrm{~h}$ prior to processing on $43 \mathrm{~d}$. A total of 366 birds were processed using males from each HWP from each pen which were randomly selected, wing-banded, and processed for determination of carcass and parts weights and yields. Following evisceration, birds were chilled in ice water for $4 \mathrm{~h}$ before deboning. 


\subsection{Statistical Analysis}

The experiment consisted of 8 treatments in a factorial arrangement of 2 hatching basket types (CTL or FAW) $\times 4$ HWP (early, pre-peak, post-peak, or late) in a split-plot design. The whole-plot factor was experimental hatching basket type ( $\mathrm{n}=13$ for main effect), and the sub-plot factor was the HWP ( $n=26$ for main effect). As such, there were 13 replicate group of each hatching basket and HWP combination. All data were analyzed using SAS 9.4 (Cary, NC, USA). The MIXED procedure was used to conduct a two-way ANOVA, with a Tukey's multiple comparison test used to separate statistically different means. Any $p \leq 0.05$ was considered statistically significant.

\section{Results}

\subsection{Organ Weights}

There was a HWP $\times$ basket type interaction $(p=0.026)$ on yolk-free BW at placement (Table 2). This interaction was because chicks in the FAW-early HWP group were $3.83 \mathrm{~g}$ heavier $(p<0.05)$ than the CTL basket chicks in the early HWP, but other HWP combinations were similar $(p>0.05)$. There were no main or interactive effects $(p>0.05)$ of basket type on absolute or relative liver or yolk weights at placement. For HWP, absolute and relative yolk weights followed the same general trend, with the highest values for the late hatchers, the lowest values for the early hatchers, and the intermediate values for the pre- and post-peak hatchers. The late HWP group also had the highest $(p=0.002)$ relative yolk weight, $12.85 \%$. The liver weights of day-old chicks had an inverse trend. Chicks from the early HWP had higher $(p=0.009)$ liver weights averaging $1.50 \mathrm{~g}$ compared to $1.22 \mathrm{~g}$ of chicks from the late HWP; other HWP showed intermediate liver weights (Table 2). The relative liver weight was also highest $(p=0.002)$ for early-HWP chicks at $3.53 \%$.

Table 2. Effects of hatch window period (HWP) and nutrient access of feed and water (FAW) or control (CTL) in the hatching basket on body, yolk, and liver weights of day-old broiler chicks.

\begin{tabular}{|c|c|c|c|c|c|}
\hline \multirow[b]{2}{*}{ Item } & \multirow[b]{2}{*}{$\begin{array}{c}\text { Yolk-Free BW } \\
\text { (g) }\end{array}$} & \multicolumn{2}{|c|}{ Yolk } & \multicolumn{2}{|c|}{ Liver } \\
\hline & & $\begin{array}{l}\text { Weight } \\
\text { (g) }\end{array}$ & $\begin{array}{c}\text { Relative to BW } \\
(\%)\end{array}$ & $\begin{array}{l}\text { Weight } \\
\text { (g) }\end{array}$ & $\begin{array}{c}\text { Relative to BW } \\
(\%)\end{array}$ \\
\hline \multicolumn{6}{|c|}{ Interaction means $(\mathrm{n}=13)$} \\
\hline Early-CTL & $36.39^{b}$ & 4.38 & 10.58 & 1.34 & 3.30 \\
\hline Early-FAW & $40.22^{\mathrm{a}}$ & 3.98 & 9.00 & 1.65 & 3.75 \\
\hline Pre-peak-CTL & $38.23^{a, b}$ & 5.06 & 12.30 & 1.32 & 2.87 \\
\hline Pre-peak-FAW & $38.25^{\mathrm{a}, \mathrm{b}}$ & 4.51 & 10.53 & 1.32 & 3.10 \\
\hline Post-peak-CTL & $39.06^{a, b}$ & 4.99 & 11.22 & 1.39 & 3.21 \\
\hline Post-peak-FAW & $38.98^{a, b}$ & 5.51 & 12.39 & 1.30 & 2.92 \\
\hline Late-CTL & $37.85^{\mathrm{a}, \mathrm{b}}$ & 5.61 & 12.80 & 1.21 & 2.81 \\
\hline Late-FAW & $38.21^{\mathrm{a}, \mathrm{b}}$ & 5.67 & 12.98 & 1.22 & 2.78 \\
\hline SEM & 0.792 & 0.397 & 0.852 & 0.084 & 0.207 \\
\hline \multicolumn{6}{|c|}{ Main effect of HWP $(n=26)$} \\
\hline Early & 38.31 & $4.18^{\mathrm{b}}$ & $9.79^{b}$ & $1.50^{\mathrm{a}}$ & $3.53^{\mathrm{a}}$ \\
\hline Pre-peak & 38.24 & $4.78^{\mathrm{a}, \mathrm{b}}$ & $11.41^{\mathrm{a}, \mathrm{b}}$ & $1.32^{\mathrm{a}, \mathrm{b}}$ & $2.98^{b}$ \\
\hline Post-peak & 39.02 & $5.25^{\mathrm{a}}$ & $11.80^{\mathrm{a}, \mathrm{b}}$ & $1.34^{\mathrm{a}, \mathrm{b}}$ & $3.06^{a, b}$ \\
\hline Late & 38.03 & $5.64^{\mathrm{a}}$ & $12.85^{\mathrm{a}}$ & $1.22^{b}$ & $2.80^{b}$ \\
\hline SEM & 0.549 & 0.276 & 0.590 & 0.058 & 0.143 \\
\hline \multicolumn{6}{|c|}{ Main effect of basket $(n=13)$} \\
\hline CTL & 37.88 & 5.01 & 11.72 & 1.31 & 3.05 \\
\hline FAW & 38.91 & 4.91 & 11.20 & 1.37 & 3.14 \\
\hline SEM & 0.381 & 0.193 & 0.410 & 0.041 & 0.099 \\
\hline \multicolumn{6}{|c|}{$p$-values } \\
\hline HWP & 0.594 & 0.002 & 0.002 & 0.009 & 0.002 \\
\hline Basket & 0.054 & 0.726 & 0.361 & 0.299 & 0.519 \\
\hline HWP $\times$ basket & 0.026 & 0.505 & 0.224 & 0.089 & 0.276 \\
\hline
\end{tabular}

a,b Means within a column that do not share a common superscript are significantly different $(p<0.05)$ as determined by a Tukey's multiple comparison test.

At d 3, yolks sampled were no longer significantly different $(p>0.05)$ in absolute or relative weight among treatment groups (Table 3 ). There was, however, a significant differ- 
ence in yolk-free BW between HWP $(p=0.040)$ and nutrient access treatments $(p=0.010)$. Liver samples at $3 \mathrm{~d}$ post-hatch no longer indicated a difference $(p>0.05)$ in relative liver weights between HWP; however, early-HWP chicks still had a higher $(p=0.022)$ absolute liver weight, $5.26 \mathrm{~g}$, compared to late-HWP chicks, $4.56 \mathrm{~g}$; other HWP were showed intermediate liver weights (Table 3). No absolute or relative liver differences were observed between basket type treatments.

Table 3. Effects of hatch window period (HWP) and nutrient access of feed and water (FAW) or control (CTL) in the hatching basket on body, yolk, and liver weights of $3 \mathrm{~d}$ old broiler chicks.

\begin{tabular}{|c|c|c|c|c|c|}
\hline \multirow[b]{2}{*}{ Item } & \multirow[b]{2}{*}{$\begin{array}{c}\text { Yolk-Free BW } \\
\text { (g) }\end{array}$} & \multicolumn{2}{|c|}{ Yolk } & \multicolumn{2}{|c|}{ Liver } \\
\hline & & $\begin{array}{l}\text { Weight } \\
\text { (g) }\end{array}$ & $\begin{array}{c}\text { Relative to BW } \\
(\%)\end{array}$ & $\begin{array}{l}\text { Weight } \\
\text { (g) }\end{array}$ & $\begin{array}{c}\text { Relative to BW } \\
(\%)\end{array}$ \\
\hline \multicolumn{6}{|c|}{ Interaction means $(\mathrm{n}=13)$} \\
\hline Early-CTL & 80.62 & 1.15 & 1.41 & 4.83 & 5.92 \\
\hline Early-FAW & 89.07 & 0.79 & 0.87 & 5.69 & 6.33 \\
\hline Pre-peak-CTL & 81.64 & 0.99 & 1.20 & 4.73 & 5.71 \\
\hline Pre-peak-FAW & 84.43 & 0.96 & 1.13 & 4.79 & 5.61 \\
\hline Post-peak-CTL & 80.00 & 0.98 & 1.22 & 4.72 & 5.80 \\
\hline Post-peak-FAW & 84.04 & 1.02 & 1.22 & 5.23 & 6.11 \\
\hline Late-CTL & 79.86 & 1.03 & 1.27 & 4.68 & 5.79 \\
\hline Late-FAW & 78.83 & 1.23 & 1.57 & 4.43 & 5.54 \\
\hline SEM & 1.912 & 0.139 & 0.175 & 0.233 & 0.228 \\
\hline \multicolumn{6}{|c|}{ Main effect of HWP $(n=26)$} \\
\hline Early & $84.85^{\mathrm{a}}$ & 0.97 & 1.14 & $5.26^{\mathrm{a}}$ & 6.13 \\
\hline Pre-peak & $83.03^{a, b}$ & 0.98 & 1.16 & $4.76^{\mathrm{a}, \mathrm{b}}$ & 5.66 \\
\hline Post-peak & $82.02^{\mathrm{a}, \mathrm{b}}$ & 1.00 & 1.22 & $4.97^{\mathrm{a}, \mathrm{b}}$ & 5.95 \\
\hline Late & $79.34^{b}$ & 1.13 & 1.42 & $4.56^{\mathrm{b}}$ & 5.66 \\
\hline SEM & 1.352 & 0.098 & 0.124 & 0.165 & 0.161 \\
\hline \multicolumn{6}{|c|}{ Main effect of basket $(n=13)$} \\
\hline CTL & $80.53^{b}$ & 1.04 & 1.28 & 4.74 & 5.80 \\
\hline FAW & $84.09^{\mathrm{a}}$ & 1.00 & 1.20 & 5.04 & 5.90 \\
\hline SEM & 0.956 & 0.0694 & 0.087 & 0.116 & 0.114 \\
\hline \multicolumn{6}{|c|}{$p$-values } \\
\hline HWP & 0.040 & 0.605 & 0.359 & 0.022 & 0.113 \\
\hline Basket & 0.010 & 0.697 & 0.533 & 0.076 & 0.565 \\
\hline HWP $\times$ Basket & 0.106 & 0.232 & 0.126 & 0.094 & 0.411 \\
\hline
\end{tabular}

a,b Means within a column that do not share a common superscript are significantly different $(p<0.05)$ as determined by a Tukey's multiple comparison test.

\subsection{Growth Performance}

At placement, chicks from FAW baskets were $1.0 \mathrm{~g}$ heavier $(p<0.001)$ than chicks from CTL baskets. The HWP also affected $(p<0.001)$ placement BW, with the later hatching chicks being the heaviest, but becoming the lightest at $7 \mathrm{~d}$ post-hatch $(p<0.001$; Table 4$)$. The effects of HWP on BW were apparent $(p \leq 0.05)$ throughout the remainder of the experiment but varied in ranking and magnitude. Chicks provided nutrient access in the hatching baskets continued to have higher BW than CTL chicks at $7 \mathrm{~d}(p<0.001), 14 \mathrm{~d}$ $(p<0.001), 21 \mathrm{~d}(p<0.001)$, and $28 \mathrm{~d}(p=0.003)$. The remainder of the $42 \mathrm{~d}$ grow-out showed no BW differences $(p>0.05)$ between basket types. During the grow-out period, no HWP $\times$ basket type interactions $(p>0.05)$ for BW were observed. Feed consumption was measured by whole pen due to the split-plot arrangement and co-rearing of chicks from different HWP. The higher BW of FAW birds up to d 28 coincided with higher BWG $(p=0.009)$ to $28 \mathrm{~d}$ and higher $(p=0.005)$ FI to $21 \mathrm{~d}$, after which, there were no differences $(p>0.05$; Table 5). Pens of FAW and CTL basket treatments had similar $(p>0.05)$ FCR throughout the $42 \mathrm{~d}$ experiment.

The average BW coefficient of variation (CV) was $8.72 \%$ at $21 \mathrm{~d}$ and $11.36 \%$ at $42 \mathrm{~d}$, and there were no differences $(p>0.05)$ among treatment groups (data not shown). Mortality was not affected $(p>0.05)$ by any of the treatments, and the cumulative average was $2.57 \%$ at $42 \mathrm{~d}$ (data not shown). 
Table 4. Body weight $(\mathrm{g})$ of broilers from different hatch window periods (HWP) within a single hatch window provided feed and water (FAW) in the hatching basket compared to a control (CTL) ${ }^{1}$.

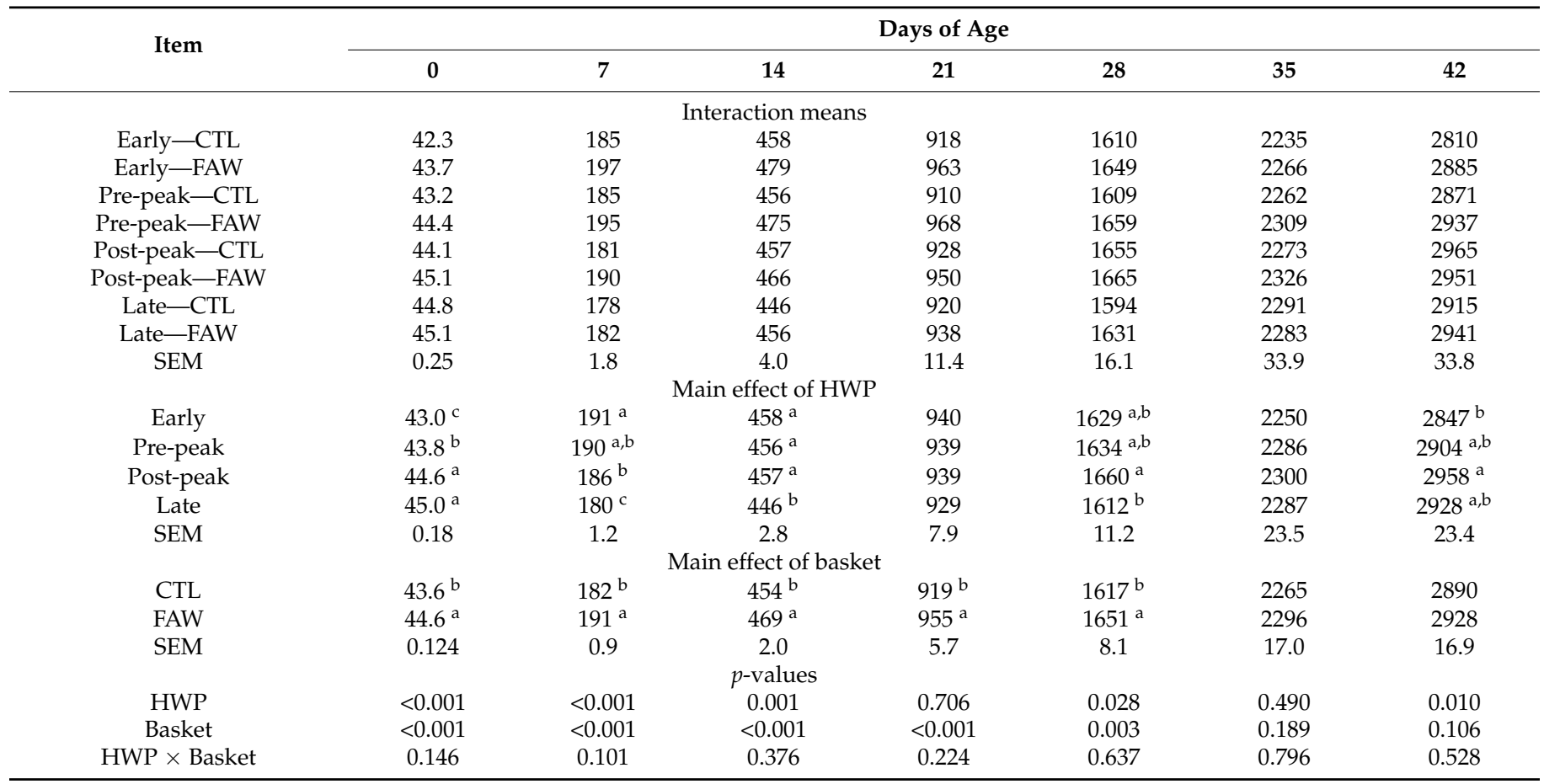

${ }^{\mathrm{a}-\mathrm{c}}$ Means within a column that do not share a common superscript are significantly different $(p<0.05)$ as determined by a Tukey's multiple comparison test. ${ }^{1}$ Mean values of $13(0 \mathrm{~d})$ or $12(7,14,21,38,35,42 \mathrm{~d})$ birds, less mortality, from each HWP in each of the 13 replicate pens of FAW or CTL basket treatment.

Table 5. Live performance of broilers provided feed and water (FAW) nutrient access in the hatching basket compared to a control (CTL) from 0 to $42 \mathrm{~d}$ post-hatch ${ }^{1}$.

\begin{tabular}{|c|c|c|c|c|}
\hline Item & CTL & FAW & SEM & $p$-Value \\
\hline & & 0 to $14 \mathrm{~d}$ & & \\
\hline BWG (g) & 410 & 424 & 2.9 & 0.002 \\
\hline FI (g) & 521 & 542 & 4.4 & 0.002 \\
\hline \multirow[t]{2}{*}{ FCR } & 1.279 & 1.287 & 0.0062 & 0.414 \\
\hline & & 14 to $28 \mathrm{~d}$ & & \\
\hline BWG (g) & BWG (g) & BWG (g) & BWG (g) & BWG (g) \\
\hline FI (g) & FI (g) & FI (g) & FI (g) & FI $(g)^{\circ}$ \\
\hline \multirow[t]{2}{*}{ FCR } & FCR & FCR & FCR & FCR \\
\hline & & 0 to $28 \mathrm{~d}$ & & \\
\hline BWG (g) & 1573 & 1606 & 8.4 & 0.009 \\
\hline FI (g) & 2541 & 2552 & 35.7 & 0.826 \\
\hline \multirow[t]{2}{*}{ FCR } & 1.619 & 1.592 & 0.0216 & 0.388 \\
\hline & & 28 to $42 \mathrm{~d}$ & & \\
\hline BWG (g) & 1275 & 1279 & 18.9 & 0.867 \\
\hline FI $(g)$ & 2722 & 2730 & 37.6 & 0.879 \\
\hline \multirow[t]{2}{*}{ FCR } & 2.135 & 2.136 & 0.0199 & 0.956 \\
\hline & & 0 to $42 \mathrm{~d}$ & & \\
\hline BWG (g) & 2848 & 2886 & 22.3 & 0.232 \\
\hline FI (g) & 5263 & 5282 & 62.8 & 0.829 \\
\hline FCR & 1.837 & 1.821 & 0.0140 & 0.419 \\
\hline
\end{tabular}

${ }^{1}$ Mean values of 13 replicate pens of FAW or CTL basket treatment.

\subsection{Processing Weights and Yields}

The ranking differences among HWP observed for the $42 \mathrm{~d}$ liver weight were again observed for the live bird weight of those selected for sampling ( $p=0.033$; Table 6$)$; however, hot and chilled carcass weights were not different $(p>0.05)$. Differences among HWP were found for hot fat pad weight $(p=0.021)$ and yield $(p=0.049)$ which were not separated by Tukey's but trended to increase in weight and yield from the early to the late HWP. A 
HWP $\times$ basket type interaction was observed for tender yield $(p=0.002$; Table 7) and wing weight $(p=0.029)$. Leg quarter weight $(p=0.009)$ and yield $(p=0.015)$ were also different among HWP. Nutrient access in the hatching basket did not have any significant effects $(p>0.05)$ on processing weights or yield.

Table 6. Processing weight and yield of broilers from different hatch window periods (HWP) within a single hatch window provided feed and water (FAW) in the hatching basket compared to a control (CTL) ${ }^{1}$.

\begin{tabular}{|c|c|c|c|c|c|c|c|}
\hline \multirow{2}{*}{ Item } & \multirow{2}{*}{$\begin{array}{c}\text { Live } \\
\text { Weight (g) }\end{array}$} & \multicolumn{2}{|c|}{ Hot Carcass } & \multicolumn{2}{|c|}{ Hot Fat Pad } & \multicolumn{2}{|c|}{ Chilled Carcass } \\
\hline & & Weight (g) & Yield (\%) & Weight (g) & Yield (\%) & Weight (g) & Yield (\%) \\
\hline \multicolumn{8}{|c|}{ Interaction means } \\
\hline Early-CTL & 3152 & 2389 & 75.74 & 46.8 & 1.49 & 2432 & 77.14 \\
\hline Early-FAW & 3200 & 2414 & 75.39 & 48.0 & 1.50 & 2457 & 76.75 \\
\hline Pre-peak-CTL & 3216 & 2424 & 75.34 & 49.1 & 1.53 & 2471 & 76.83 \\
\hline Pre-peak-FAW & 3242 & 2442 & 75.29 & 46.4 & 1.42 & 2484 & 76.61 \\
\hline Post-peak-CTL & 3296 & 2478 & 75.17 & 50.8 & 1.55 & 2525 & 76.58 \\
\hline Post-peak-FAW & 3263 & 2456 & 75.24 & 50.8 & 1.52 & 2503 & 76.70 \\
\hline Late-CTL & 3250 & 2433 & 74.87 & 50.8 & 1.57 & 2480 & 76.28 \\
\hline Late-FAW & 3192 & 2390 & 74.86 & 52.2 & 1.64 & 2431 & 76.14 \\
\hline SEM & 39.2 & 32.6 & 0.346 & 1.88 & 0.058 & 33.2 & 0.362 \\
\hline \multicolumn{8}{|c|}{ Main effect of hatch period } \\
\hline Early & $3176^{\mathrm{b}}$ & 2401 & 75.56 & 47.4 & 1.49 & 2445 & 76.95 \\
\hline Pre-peak & $3229^{a, b}$ & 2433 & 75.32 & 47.8 & 1.48 & 2478 & 76.72 \\
\hline Post-peak & $3280^{a}$ & 2467 & 75.20 & 50.8 & 1.54 & 2514 & 76.64 \\
\hline Late & $3221^{a, b}$ & 2411 & 74.87 & 51.5 & 1.60 & 2455 & 76.21 \\
\hline SEM & 26.1 & 21.7 & 0.231 & 1.25 & 0.039 & 22.1 & 0.242 \\
\hline \multicolumn{8}{|c|}{ Main effect of basket } \\
\hline CTL & 3229 & 2431 & 75.28 & 49.4 & 1.53 & 2477 & 76.71 \\
\hline FAW & 3224 & 2425 & 75.20 & 49.4 & 1.52 & 2469 & 76.55 \\
\hline \multirow[t]{2}{*}{ SEM } & 18.1 & 15.1 & 0.160 & 0.86 & 0.027 & 15.3 & 0.167 \\
\hline & & & $p$-values & & & & \\
\hline HWP & 0.033 & 0.105 & 0.157 & 0.021 & 0.049 & 0.088 & 0.140 \\
\hline Basket & 0.868 & 0.783 & 0.692 & 0.993 & 0.685 & 0.684 & 0.477 \\
\hline HWP $\times$ basket & 0.390 & 0.602 & 0.917 & 0.574 & 0.329 & 0.583 & 0.882 \\
\hline
\end{tabular}

a,b Means within a column that do not share a common superscript are significantly different $(p<0.05)$ as determined by a Tukey's multiple comparison test. ${ }^{1}$ Mean values of 4 male birds randomly sampled from each HWP within each of 13 replicate pens per basket treatment.

Table 7. Processing weight and yield of broilers from different hatch window periods (HWP) within a single hatch window provided feed and water (FAW) in the hatch basket compared to a control (CTL) ${ }^{1}$.

\begin{tabular}{|c|c|c|c|c|c|c|c|c|}
\hline \multirow{2}{*}{ Item } & \multicolumn{2}{|c|}{ Breast } & \multicolumn{2}{|c|}{ Tender } & \multicolumn{2}{|c|}{ Leg Quarter } & \multicolumn{2}{|c|}{ Wing } \\
\hline & Weight (g) & Yield (\%) & Weight (g) & Yield (\%) & Weight (g) & Yield (\%) & Weight (g) & Yield (\%) \\
\hline \multicolumn{9}{|c|}{ Interaction means } \\
\hline Early-CTL & 656.3 & 20.78 & 134.8 & $4.28^{a}$ & 703.9 & 22.34 & 252.2 & 8.01 \\
\hline Early-FAW & 647.9 & 20.22 & 133.6 & $4.18^{\mathrm{a}, \mathrm{b}}$ & 721.1 & 22.53 & 261.7 & 8.18 \\
\hline Pre-peak-CTL & 652.4 & 20.26 & 134.5 & $4.18^{\mathrm{a}, \mathrm{b}}$ & 737.1 & 22.93 & 254.9 & 7.93 \\
\hline Pre-peak-FAW & 668.9 & 20.58 & 136.9 & $4.22^{\mathrm{a}}$ & 733.0 & 22.59 & 259.6 & 8.02 \\
\hline Post-peak-CTL & 672.5 & 20.36 & 136.9 & $4.15^{\mathrm{a}, \mathrm{b}}$ & 741.6 & 22.51 & 266.7 & 8.10 \\
\hline Post-peak-FAW & 667.9 & 20.41 & 137.0 & $4.19^{\mathrm{a}}$ & 734.6 & 22.48 & 259.3 & 7.96 \\
\hline Late-CTL & 664.9 & 20.43 & 129.7 & $3.99^{b}$ & 721.3 & 22.20 & 260.0 & 8.01 \\
\hline Late-FAW & 643.9 & 20.17 & 135.1 & $4.23^{\mathrm{a}}$ & 710.6 & 22.25 & 254.5 & 7.98 \\
\hline SEM & 12.51 & 0.244 & 2.26 & 0.049 & 10.53 & 0.190 & 3.66 & 0.079 \\
\hline \multicolumn{9}{|c|}{ Main effect of HWP } \\
\hline Early & 652.1 & 20.50 & 134.2 & 4.23 & $712.5^{b}$ & $22.43^{\mathrm{a}, \mathrm{b}}$ & 257.0 & 8.09 \\
\hline Pre-peak & 660.7 & 20.42 & 135.7 & 4.20 & $735.1^{\mathrm{a}, \mathrm{b}}$ & $22.76^{a}$ & 257.2 & 7.98 \\
\hline Post-peak & 670.2 & 20.38 & 137.0 & 4.14 & $738.1^{\mathrm{a}}$ & $22.50^{\mathrm{a}, \mathrm{b}}$ & 263.0 & 8.03 \\
\hline Late & 654.4 & 20.30 & 132.4 & 4.11 & $715.9^{\mathrm{ab}}$ & $22.22^{b}$ & 257.2 & 7.99 \\
\hline SEM & 8.34 & 0.163 & 1.51 & 0.033 & 7.02 & 0.127 & 2.44 & 0.052 \\
\hline \multicolumn{9}{|c|}{ Main effect of basket } \\
\hline Control & 661.5 & 20.46 & 134.0 & 4.15 & 726.0 & 22.50 & 258.4 & 8.01 \\
\hline FAW & 657.2 & 20.34 & 135.7 & 4.20 & 724.8 & 22.46 & 258.8 & 8.03 \\
\hline SEM & 5.77 & 0.113 & 1.04 & 0.023 & 4.86 & 0.088 & 1.69 & 0.036 \\
\hline \multicolumn{9}{|c|}{${ }^{1.04} p$-values } \\
\hline HWP & 0.359 & 0.844 & 0.114 & 0.053 & 0.009 & 0.015 & 0.161 & 0.364 \\
\hline Basket & 0.579 & 0.455 & 0.237 & 0.097 & 0.859 & 0.774 & 0.886 & 0.648 \\
\hline HWP $\times$ basket & 0.387 & 0.216 & 0.388 & 0.002 & 0.476 & 0.445 & 0.029 & 0.134 \\
\hline
\end{tabular}

a,b Means within a column that do not share a common superscript are significantly different $(p<0.05)$ as determined by a Tukey's multiple comparison test. ${ }^{1}$ Mean values of 4 male birds randomly sampled from each HWP within each of 13 replicate pens per basket treatment.

\section{Discussion}

The current study was based on having equal hatch window representation in each pen to reflect the effects of hatching basket feeding when chicks hatching from different 
periods of the hatch window were commingled, as would be the scenario in commercial production. Though the normal distribution of a typical hatch window would not result in equal representation of all HWP for the flock, equally stratifying birds from all HWP into each pen provided a more valid design for statistical analysis in the current experiment. The comparison of $0 \mathrm{~d}$ yolk samples showed that HWP affected the amount of absolute and relative yolk weight. Assuming a similar initial yolk weight, the earlier hatching chicks had more time outside of the egg and thus utilized more yolk. The liver weight, on the other hand, was higher for the early-HWP chicks compared to the late-HWP and intermediate for other HWP. This somewhat inverse relationship between yolk and liver size at placement may indicate a mobilization of yolk nutrients and energy to support tissue growth, especially for organs that have a high allometric priority during early growth such as the liver [2], though additional compositional analyses of liver and yolk nutrient profiles would be needed to confirm this. Chicks from FAW baskets had similar yolk weights to CTL chicks; however, they showed a tendency for higher yolk-free BW that corresponded with a higher placement weight. These chicks were likely more hydrated and were observed to have full crops at placement, which also would have added to their total BW. Average absolute and relative yolk sac weights decreased from approximately 5 to $1 \mathrm{~g}$ and 11 to $1 \%$ from 0 to $3 \mathrm{~d}$ of age and indicated that chicks quickly utilized their yolk sacs during this period. At $3 \mathrm{~d}$ post-hatch, the ranking of liver weights by HWP was similar to that observed at $0 \mathrm{~d}$. Liver and yolk sac weight differences among hatch times diminished during early growth, which is supported by hatch moment studies by Lamot et al. [13] who found no differences in liver or yolk sac weight at $4 \mathrm{~d}$ post-hatch.

During the grow-out, both basket type and HWP independently affected the performance of the broilers, but the effects of each factor varied among time points. Early-hatching birds were lighter at placement than birds from other HWP, but interestingly became heavier than the post-peak and late-HWP chicks at $7 \mathrm{~d}$. There was clearly a faster growth rate in order for this compensation occur, but due to the pen arrangement in which birds from all HWP shared a common feeder, we were unable to identify if this compensation in BW was due to increased FI, better FCR, or both. This is in agreement with studies by Lamot et al. [13] who also found that earlier-hatching chicks were initially lighter, but had accelerated growth after placement as a result of higher FI, which combined with a longer amount of growth time, allowed them to become heavier than their later-hatching counterparts by $4 \mathrm{~d}$ post-hatch, though this study ended at $18 \mathrm{~d}$. In the current experiment, the final $42 \mathrm{~d}$ BW of the early HWP was again lower that of chicks from post-peak HWP, indicating that the early compensatory gain may not be sustained to market ages, though ranking in BW varied among HWP between 14 and $42 \mathrm{~d}$. Thus, while HWP does seem to influence growth rate, more mechanistic evaluation of these effects are necessary to fully understand the relationship between HWP and growth potential.

Chicks from FAW baskets were heavier than CTL birds at each time point to $28 \mathrm{~d}$. This was likely driven by an early initiation of feed consumption in the hatcher as shown by a $1 \mathrm{~g}$ BW advantage at placement, and the higher FI to $21 \mathrm{~d}$ supported higher BWG to $28 \mathrm{~d}$. Beyond $28 \mathrm{~d}$, the FAW birds were similar in BW to the birds from CTL baskets. Converging BW of hatch basket fed and control chicks at $28 \mathrm{~d}$ of age were also reported by Hollemans et al. [12]. Sklan et al. [8] observed effects of hatch basket feeding in a shorter $21 \mathrm{~d}$ experiment during which fed chicks exhibited higher BW for the trial duration. The type of early feeding, time of initiation, and duration of fasting for control chicks and duration of the grow-out have all led to varying degrees of success with approaches to early feeding. For example, Kidd et al. [14] fed chicks in trays during post-hatch, pre-placement holding and did not observe any differences in BW, feed efficiency, or mortality among treatments beyond $7 \mathrm{~d}$ of age.

Providing water and feed in hatching baskets does allow immediate access to nutrients once a chick hatches and also initiates feeding and growth at differing times for the same hatch of chicks to be reared together. Therefore, BW CV were considered important to evaluate uniformity among treatments as an indicator of overall broiler health and 
performance [15]. The CV for all treatment groups and low cumulative mortality indicated this was a well-performing flock. Perhaps, a more challenging environment would have generated noticeable differences among the groups, since the current experiment utilized eggs from a prime-age breeder flock and fresh litter. Further, a longer post-hatch holding period to simulate stress associated with extended transport times may have resulted in a different response to hatching tray feed access than observed in the current experiment.

Live weight differences among HWP at $42 \mathrm{~d}$ were similar in relation to the live weights at processing, where the post-peak HWP group was heavier than the early HWP chicks, with other groups having intermediate weights. These weights were overall heavier than BW in Table 4 due to the sub-sample of only males being used for processing. Fat pad weight and yield differences among HWP were also detected, which may reflect differences in body composition and feed efficiency, but this cannot be confirmed due to the common pen rearing of all HWP and a lack of more extensive body composition analyses. Processing data at $42 \mathrm{~d}$ surprisingly revealed a HWP $\times$ basket type interaction for tender yield that was due to a decrease in tender yield from early- to late-HWP groups for the CTL group, while tender yields for FAW groups were similar across all HWP. An interaction was also observed for wing weight, whereby FAW access tended to increased wing weight for early and pre-peak hatchers but generally decreased wing weight for post-peak and latehatching chicks. The leg quarter weight and yield were the only processing measurements independently influenced by HWP. The absolute leg quarter weight ranked the same among HWP as the live weights, but interestingly, this was the only part that was statistically separated. This may indicate that differences in dark meat accretion may have been more influenced by HWP than breast muscle accretion.

\section{Conclusions}

In conclusion, results from this experiment indicate that feed and water access in the hatcher may lead to higher chick weights at placement and increase the weight of broilers during the first $28 \mathrm{~d}$ of growth. However, feed and water access in the hatcher had no influence on final $42 \mathrm{~d}$ body weight, processing yield, FCR, or mortality. These findings also highlighted an intriguing BW compensation of early-hatching chicks, which were lighter at hatch but became heavier than their later-hatching counterparts at $7 \mathrm{~d}$, with varying weight differences at later ages. The current study generally showed merging of weights by basket type and compensation of BW by HWP, suggesting that the BW of broilers at placement or $7 \mathrm{~d}$ may not always be an accurate predictor of BW at market. This is important in reviewing similar early post-hatch feeding studies due to the fact that none, to the authors' knowledge, have processed or grown birds beyond $21 \mathrm{~d}$ without fasting for extended periods. Further research using varying holding times and hatch window lengths, in addition to more challenging environmental conditions (e.g., heat stress, transport stress, or sub-clinical disease) would assist in determining if and when hatching basket feeding yields an advantage at market and processing.

Author Contributions: Conceptualization, J.R.D., R.K.B., F.D.C. and S.J.R.; methodology J.R.D., D.E.Y. and S.J.R.; writing—original draft preparation, J.R.D.; writing—review and editing, J.R.D., F.D.C. and S.J.R.; project administration, F.D.C. and S.J.R.; funding acquisition, R.K.B. and F.D.C. All authors have read and agreed to the published version of the manuscript.

Funding: This research was funded in part by Jamesway Incubator Company, Inc. (Cambdridge, ON, Canada) and the Agricultural Experiment Station of the University of Arkansas System Division of Agriculture.

Institutional Review Board Statement: All animal care and experimental procedures in this study were approved by the University of Arkansas Institutional Animal Care and Use Committee prior to initiation of the experiment (Protocol \# 18069, approved 9 January 2018).

Data Availability Statement: Data are available on request from the corresponding author. 
Acknowledgments: The authors express appreciation to George's, INC (Springdale, AR, USA) for their donation of the fertile hatching eggs used in this experiment.

Conflicts of Interest: The authors declare no conflict of interest.

\section{References}

1. Zuidhof, M.J.; Schneider, B.L.; Carney, V.L.; Korver, D.R.; Robinson, F.E. Growth, efficiency, and yield of commercial broilers from 1957, 1978, and 2005. Poult. Sci. 2014, 93, 1-13. [CrossRef] [PubMed]

2. Noy, Y.; Sklan, D. Yolk and exogenous feed utilization in the posthatch chick. Poult. Sci. 2001, 80, 1490-1495. [CrossRef] [PubMed]

3. Noy, Y.; Sklan, D. Different types of early feeding and performance in chicks and poults. J. Appl. Poult. Res. 1999, 8, 16-24. [CrossRef]

4. Pinchasov, Y.; Noy, Y. Comparison of post-hatch holding time and subsequent early performance of broiler chicks and turkey poults. Br. Poult. Sci. 1993, 34, 111-120. [CrossRef]

5. Vieira, S.L.; Moran, E.T. Effects of delayed placement and used litter on broiler yields. J. Appl. Poult. Res. 1999, 8, 75-81. [CrossRef]

6. Bigot, K.; Mignon-Grasteau, S.; Picard, M.; Tesseraud, S. Effects of delayed feed intake on body, intestine, and muscle development in neonate broilers. Poult. Sci. 2003, 82, 781-788. [CrossRef] [PubMed]

7. Noy, Y.; Sklan, D. Energy utilization in newly hatched chicks. Poult. Sci. 1999, 78, 1750-1756. [CrossRef] [PubMed]

8. Sklan, D.; Nox, Y.; Hoyzman, A.; Rozenboim, I. Decreasing weight loss in the hatchery by feeding chicks and poults in hatching trays. J. Appl. Poult. Res. 2000, 9, 142-148. [CrossRef]

9. Casteel, E.T.; Wilson, J.L.; Buhr, R.J.; Sander, J.E. The influence of extended posthatch holding time and placement density on broiler performance. Poult. Sci. 1994, 73, 1679-1684. [CrossRef] [PubMed]

10. Noy, Y.; Uni, Z. Early nutritional strategies. Worlds. Poult. Sci. J. 2010, 66, 639-646. [CrossRef]

11. Willemsen, H.; Debonne, M.; Swennen, Q.; Everaert, N.; Careghi, C.; Han, H.; Bruggeman, V.; Tona, K.; Decuypere, E. Delay in feed access and spread of hatch: Importance of early nutrition. Worlds. Poult. Sci. J. 2010, 66, 177-188. [CrossRef]

12. Hollemans, M.S.; Vries, S.; Lammers, A.; Clouard, C. Effects of early nutrition and transport of 1-day-old chickens on production performance and fear response. Poult. Sci. 2018, 97, 2534-2542. [CrossRef] [PubMed]

13. Lamot, D.M.; van de Linde, I.B.; Molenaar, R.; van der Pol, C.W.; Wijtten, P.J.; Kemp, B.; van den Brand, H. Effects of moment of hatch and feed access on chicken development. Poult. Sci. 2014, 93, 2604-2614. [CrossRef] [PubMed]

14. Kidd, M.T.; Taylor, J.W.; Page, C.M.; Lott, B.D.; Chamblee, T.N. Hatchery feeding of starter diets to broiler chicks. J. Appl. Poult. Res. 2007, 16, 234-239. [CrossRef]

15. Cobb-Vantress, Inc. Cobb Broiler Management Guide; Cobb-Vantress, Inc.: Siloam Springs, AR, USA, 2018. 